\title{
Symptom Dimensions in OCD: Item-Level Factor Analysis and Heritability Estimates
}

\author{
Hilga Katerberg • Kevin L. Delucchi · S. Evelyn Stewart • Christine Lochner • \\ Damiaan A. J. P. Denys • Denise E. Stack • J. Michael Andresen • \\ J. E. Grant • Suck W. Kim • Kyle A. Williams • Johan A. den Boer • \\ Anton J. L. M. van Balkom • Johannes H. Smit • Patricia van Oppen • \\ Annemiek Polman • Michael A. Jenike • Dan J. Stein · Carol A. Mathews • \\ Danielle C. Cath
}

Received: 28 May 2009/Accepted: 19 January 2010/Published online: 2 April 2010

(c) The Author(s) 2010. This article is published with open access at Springerlink.com

\begin{abstract}
To reduce the phenotypic heterogeneity of obsessive-compulsive disorder (OCD) for genetic, clinical
\end{abstract}

Edited by Michael Lyons.

Hilga Katerberg and Kevin L. Delucchi contributed equally to this work.

H. Katerberg · J. A. den Boer · A. Polman

Department of Psychiatry, University Medical Center

Groningen, University of Groningen, Groningen,

The Netherlands

H. Katerberg · A. J. L. M. van Balkom .

J. H. Smit · P. van Oppen

GGZ Buitenamstel, Amsterdam, The Netherlands

K. L. Delucchi · C. A. Mathews

Department of Psychiatry, University of California,

San Francisco, CA, USA

S. E. Stewart - M. A. Jenike

Pediatric Obsessive-Compulsive Disorder Clinic,

Massachusetts General Hospital, Boston, MA, USA

\section{S. E. Stewart}

Psychiatric and Neurodevelopmental Genetics Unit, Harvard Medical School, Massachusetts General Hospital,

Boston, MA, USA

S. E. Stewart - D. E. Stack - M. A. Jenike

Obsessive-Compulsive Disorder Institute, McLean Hospital,

Belmont, MA, USA

C. Lochner - D. J. Stein

MRC Unit on Anxiety \& Stress Disorders, Department of Psychiatry, University of Stellenbosch, Stellenbosch, South Africa

D. A. J. P. Denys

Department of Psychiatry, Academic Medical Center,

University of Amsterdam, Amsterdam, The Netherlands and translational studies, numerous factor analyses of the Yale-Brown Obsessive Compulsive Scale checklist (YBOCS-CL) have been conducted. Results of these analyses have been inconsistent, likely as a consequence of

J. M. Andresen

Massachusetts Institute of Technology, Cambridge,

MA, USA

J. E. Grant

Department of Psychiatry, University of Minnesota

Medical School, Minneapolis, USA

S. W. Kim

Department of Psychiatry, University of Minnesota, Minneapolis, MI, USA

K. A. Williams

Department of Neurology, University of Minnesota, Minneapolis, MI, USA

A. J. L. M. van Balkom - J. H. Smit · P. van Oppen Department of Psychiatry, VU University Medical Center, Amsterdam, The Netherlands

D. J. Stein

Department of Psychiatry, University of Cape Town, Cape Town, South Africa

D. C. Cath $(\bowtie)$

Department of Clinical and Health Psychology,

Altrecht outpatient anxiety services, Utrecht University, Mimosastraat 2-4, 3551 DC Utrecht, The Netherlands

e-mail: dcath@xs4all.nl 
small sample sizes and variable methodologies. Furthermore, data concerning the heritability of the factors are limited. Item and category-level factor analyses of YBOCS-CL items from 1224 OCD subjects were followed by heritability analyses in 52 OCD-affected multigenerational families. Item-level analyses indicated that a five factor model: (1) taboo, (2) contamination/cleaning, (3) doubts, (4) superstitions/rituals, and (5) symmetry/hoarding provided the best fit, followed by a one-factor solution. All 5 factors as well as the one-factor solution were found to be heritable. Bivariate analyses indicated that the taboo and doubts factor, and the contamination and symmetry/ hoarding factor share genetic influences. Contamination and symmetry/hoarding show shared genetic variance with symptom severity. Nearly all factors showed shared environmental variance with each other and with symptom severity. These results support the utility of both OCD diagnosis and symptom dimensions in genetic research and clinical contexts. Both shared and unique genetic influences underlie susceptibility to OCD and its symptom dimensions.

Keywords OCD - Factor analysis - Heritability · Symptom dimensions · Y-BOCS · Genetic - Severity · Onset

\section{Introduction}

Obsessive-compulsive disorder (OCD) is a neuropsychiatric condition that affects $1-2 \%$ of the population worldwide and is characterized by intrusive, recurrent thoughts, feelings, and ideas (obsessions) and/or repetitive actions, often aimed at reducing tension or anxiety accompanying obsessions (compulsions) (American Psychiatric Association 1994; Fontenelle and Hasler 2008).

OCD is phenomenologically and etiologically heterogeneous (Mataix-Cols et al. 2007). Phenomenologically, OCD-affected individuals vary widely with respect to symptom type (e.g., hoarding vs. cleaning), symptom severity, age of symptom onset, and comorbidities (e.g., tic disorders, depression, grooming disorders, etc.). Further, genetic epidemiology studies suggest that OCD is genetically complex, with multiple genetic and environmental factors contributing to its development (for an overview: see Pauls 2008). The heterogeneity of OCD symptoms may contribute to the difficulty in identifying susceptibility genes that confer vulnerability to specific components of the disorder. It may also dilute findings emergent from other etiological, clinical, and treatment studies. One of the various approaches to minimize OCD heterogeneity that has received support from neuroimaging, treatment, and genetic studies is the use of symptom-based rather than disorder- or syndrome-based constructs, based on the belief that underlying symptom dimensions may reflect more etiological homogeneity than a global OCD diagnosis (Mataix-Cols et al. 2005).

Obsessive-compulsive (OC) symptomatology is predominantly measured with the Yale-Brown Obsessive Compulsive Scale (YBOCS), which includes an assessment of OC symptom severity and a symptom checklist (YBOCS-CL) containing 45 obsessions and 29 compulsions within 15 predefined symptom categories (Goodman et al. $1989 \mathrm{a}, \mathrm{b})$. To reduce the phenomenological heterogeneity of OCD, several factor analyses have been performed using the YBOCS-CL (Baer 1994; Cavallini et al. 2002; Cullen et al. 2007; Delorme et al. 2006; Denys et al. 2004; Feinstein et al. 2003; Girishchandra and Khanna 2001; Hasler et al. 2005, 2007; Kim et al. 2005; Leckman et al. 1997; Mataix-Cols et al. 1999, 2005, 2008; McKay et al. 2006; Pinto et al. 2008; Stein et al. 2007, 2008; Stewart et al. 2007, 2008; Wu et al. 2007). The majority of these studies identified three or four main symptom dimensions based on factor analyses of 13 symptom categories, rather than using individual items within categories. This is likely due to methodological constraints and concerns about small sample sizes. A recent meta-analysis of twenty-one symptom category-based factor analyses identified four OC symptom dimensions: (1) symmetry obsessions; counting, ordering and arranging compulsions; (2) obsessions and checking (aggressive, sexual, religious and somatic obsessions; and related checking compulsions); (3) contamination/cleaning, and (4) hoarding (Bloch et al. 2008).

Although clinically useful, the category-based approach to factor analysis is limited by the fact that individual symptoms have been grouped into predefined YBOCS-CL symptom categories (designed to fit a presupposed theoretical model), which may not actually cluster together if assessed separately. In addition, the YBOCS-CL "miscellaneous" obsessions and compulsions categories are usually excluded from category-driven analyses, limiting complete data availability for analyses of the OCD phenotype. Therefore, symptom dimensions resulting from category-driven analyses may have biases that are not present in item-driven analyses (Denys et al. 2004; Feinstein et al. 2003).

To address this limitation, eight studies (Table 1) have been published on exploratory factor analyses using individual items from the YBOCS-CL (Denys et al. 2004; Feinstein et al. 2003; Girishchandra and Khanna 2001; Hantouche and Lancrenon 1996; Pinto et al. 2008; Stein et al. 2007; Stein et al. 2007, 2008; Wu et al. 2007). Although the factors identified in these studies partially overlap with category-based factors, a key difference is that nearly all item-based analyses report 5 rather than 4 final 


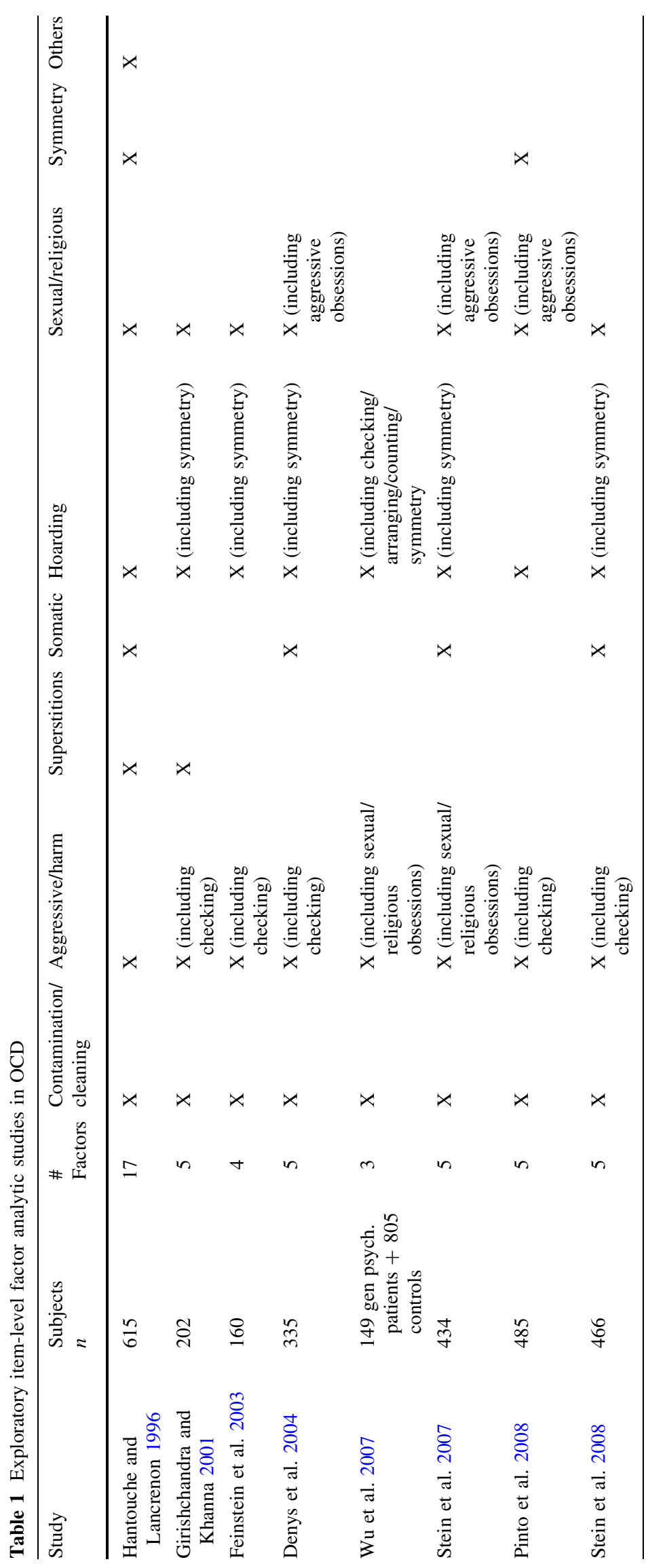


factors: (1) symmetry and repeating, ordering and counting; (2) aggressive, sexual and religious obsessions; (3) contamination and cleaning; (4) aggressive obsessions and checking, and (5) somatic obsessions (Bloch et al. 2008). Relationships identified to date between symptom dimensions and clinical characteristics include hoarding and older age (Samuels et al. 2008), washing and female sex (Labad et al. 2008), and all symptom dimensions and familiality (Hasler et al. 2007).

Although OCD is to some extent heritable, it is etiologically complex (Pauls 2008). It has been suggested that OC symptom dimensions may be more heritable than OCD diagnosis per se (Alsobrook et al. 1999; Hasler et al. 2007). Although some studies examining the heritability of OC symptom dimensions have been published, this area has not yet been investigated comprehensively. There have been few clinical OCD twin studies, and these are limited by small sample sizes (less than 100 twin pairs). The only twin study examining heritability of obsessive-compulsive (OC) symptom dimensions used a population-based rather than an OCD-affected sample of twin pairs. This study identified three OC symptom dimensions, including rumination, contamination and checking, which all shared variation with one latent common factor (i.e., OC behavior). Variation within the common factor was explained by both genes (36\%) and environmental factors (64\%). Only the contamination dimension was influenced by specific genes and seemed relatively independent (van Grootheest et al. 2008).

Another method of examining the heritability of a trait of interest (such as OCD) is to use a family-based approach, either via affected sibling pairs or pedigrees. This approach benefits from utilizing families that are enriched for the trait of interest. The pedigree approach has the additional advantage of statistical power, even with small samples, provided that families with multiple siblings and generations and distant relative pair relationships are included (Schork 1993). Family-based approaches to examine heritability of OC symptom dimensions have, thus far, been wholly inconclusive. An early family study suggested that symmetry and ordering symptoms had a significant genetic component (Alsobrook et al. 1999), and subsequent studies found significant intra-class correlations in independent sib pairs for symmetry/ordering and hoarding (Cullen et al. 2007) and for contamination/ cleaning and hoarding (Chacon et al. 2007). In the OCD Collaborative Genetics Study, significant sib-sib associations were identified for four factors, with hoarding and taboo thoughts being the most robustly familial (Hasler et al. 2007; Pinto et al. 2008). At the same time, heritability for the one-factor OC symptom dimension model may be greater than that for any specific symptom dimension within other models. In a study of multigenerational families with OCD and hoarding, overall OC symptoms had higher heritability than hoarding symptoms, although both were heritable (Mathews et al. 2007).

In summary, the utility of OC symptom dimensions as alternative phenotypes for genetic studies have not yet fully converged. Moreover, the heritability of OC symptom dimensions has not been fully examined. This study aims to: (1) identify homogeneous symptom dimensions via item-level factor analysis on a large heterogeneous OCD patient sample; (2) examine potential associations between identified symptom dimensions and selected clinical characteristics; and (3) conduct heritability analyses on identified factors in a subset of OCD families.

\section{Methods}

This project encompasses a joint venture between the Department of Psychiatry of the University of California in San Francisco, the Department of Psychiatry of McLean and Massachusetts General Hospitals at Harvard Medical School, GGZ Buitenamstel Amsterdam, the Department of Psychiatry of the University Medical Center Groningen, the MRC Research Unit on Anxiety Disorders and the MRC/US Centre for Molecular and Cellular Biology, University of Stellenbosch in South Africa, and the Departments of Psychiatry, Neurology, and Laboratory Medicine at the University of Minnesota.

\section{Participants included in factor analyses}

Data from the YBOCS-CL were pooled for analyses from 1224 study participants with a lifetime history of OCD based on DSM-IV criteria, collected at five sites: San Francisco $(n=124)$, Boston $(n=329)$, Amsterdam $(n=$ $229)$, Stellenbosch $(n=393)$, and Groningen $(n=149)$. All diagnoses were established according to DSM-IV criteria (American Psychiatric Association 1994) using the Structured Clinical Interview for Axis I disorders (SCID-I/ P) (First et al. 1998), the Mini International Neuropsychiatric Interview (MINI) version 5.0.0 (Sheehan et al. 1998), or expert clinician diagnosis (Stewart et al. 2005). The study was approved by the Medical Ethical Review boards of all participating centers. All subjects (in addition to the parents of minors) gave written informed consent for participation in the study.

OCD-affected probands from the San Francisco sample were recruited for previously described genetic and phenomenological studies (Chavira et al. 2008). Subjects from Boston were patients recruited during a first admission to the McLean OCD Institute. A subpopulation of these subjects participated in a study of the effectiveness of intensive residential treatment for severe, refractory OCD (Stewart et al. 2005). Subjects from Amsterdam were 
recruited from an anxiety outpatient clinic. Subjects from Stellenbosch were recruited by physician referral, media advertisements, the Mental Health Information Centre (MHIC) and the OCD Association of South Africa (OCDSA), as described previously (Hemmings et al. 2008). The Groningen subjects were recruited for genetic and treatment studies of OCD by physician referral, media advertisements and the Dutch patient association for anxiety disorders. The majority of the study population $(>90 \%)$ was of Caucasian descent.

\section{Participants included in heritability analyses}

The subsample for heritability analyses comprised 52 OCD-probands from the San Francisco site and all family members for whom YBOCS information was available ( $N=204$, total $N=258$ ). Families ranged in size between 2 and 55 individuals, with a mean of 5 persons per family. The families all consisted of individuals from a minimum of two generations (parent and child), with the largest family encompassing four generations. There were an average of $2.7 \mathrm{OCD}$-affected individuals per family (range 1 to 16$)$ and $61.5 \%$ of the family sample was female. The mean ages at interview and at OCD symptom onset were 37.2 years and 9.1 years, respectively.

Participants included in regression analyses on clinical characteristics

In the analyses on the associations between gender, age at assessment and age at onset on the one hand and factor scale scores on the other, 1024 patients were included. In the analyses on relationships between familiality and factor scale scores, 353 patients were included ( $n=124$ from San Francisco, $n=229$ from Amsterdam).

\section{Data collection}

All interviews were carried out by trained psychologists. The YBOCS-CL (Goodman et al. 1989a, b) was used to assess OC symptoms in all study subjects. Although debate exists regarding the quality of data generated by the YBOCS-CL due to limited availability of psychometric data, its length and representativeness with respect to the OCD phenotype, the scale is regarded as the gold standard in assessment of OC symptoms.. The items of the scale were completed by self-report. Each positively rated item was subsequently validated by interview. Items were coded as "0" when the patient never had the symptom and as " 1 " when the symptom was reported in the past and/or present. All 74 items of the original published version (Goodman et al. 1989a, b), including miscellaneous items, were used in analyses.
The Yale-Brown Obsessive-Compulsive Severity Scale (YBOCS-SS) (Goodman et al. 1989a, b) was used to assess worst ever (San Francisco) or present (Groningen, Amsterdam, Stellenbosch and Boston) severity of OC symptoms. In addition, age of onset of OC symptoms was determined. Family history of OC symptoms (i.e., the presence of $\mathrm{OC}$ symptoms in at least one family member) was recorded for the Boston and Amsterdam sites. No site data are available on inter-rater reliability.

\section{Analysis methods}

The distribution of all 74 YBOCS-CL items was examined. Ten of the items labeled "other" were excluded from analysis due to their heterogeneity (e.g., "other contamination obsessions"). The YBOCS-CL has two symmetry items: "symmetry obsession accompanied by magical thinking" and "symmetry obsession not accompanied by magical thinking". Since two sites did not make a distinction on presence or absence of magical thinking, one symmetry item was created for all patients. This resulted in the ultimate inclusion of 63 YBOCS-CL items in the exploratory factor analyses.

\section{Exploratory and confirmatory factor analyses}

Exploratory principal component factor analyses with varimax rotation (to produce the clearest distinctions between the resulting factors) were conducted on the 63 YBOCS-CL items using SAS (v9.1.3) with tetrachoric correlation coefficient estimates used for the item-level correlation matrix (via the \% polychor macro). All available data were used in the analyses. The scree plot was examined, and only factors with an eigenvalue $>1$ were retained.

Confirmatory factor analyses for models comprising 4-8 factors were then performed using Mplus (v4.2) to determine the model with the most parsimonious fit. The factor analysis estimation was based upon weighted least-squares estimates using a diagonal weight matrix. Items were assigned to a factor if they had a loading $\geq 0.4$ on that factor. Items that cross-loaded (i.e., with a loading of $>0.3$ on three or more factors), items that did not load $\geq 0.4$ on any factor, and items that were unstable across models (i.e., loaded on very different factors from model to model) were omitted from the confirmatory analyses.

To establish the optimal number of factors and factor constitution for the best-fit model, the following fit indices were used: the chi-square fit-statistic, the comparative fit index (CFI), the Tucker-Lewis Index (TLI), the Root Mean Square Error of Approximation (RMSEA) and the Weighted Root Mean Square Residual (WRMR). Values of the CFI and of TLI approaching 0.95 , values approaching 
0.08 of the WRMR, and values of the RMSEA $<0.05$ were used as accepted general indicators of a good fit (Browne and Cudek 1993; Hu and Bentler 1999).

In addition, a principal components analysis using the category-based approach with promax rotation was performed for purposes of comparison. For this analysis, missing items in the YBOCS-CL severity scale were imputed using Solas ${ }^{\mathrm{TM}} 3.2$ (statistical solutions, ltd; Cork, Ireland) using predictive model-based imputation. Missing variables were imputed five times, yielding five complete datasets, as recommended by Schafer (Schafer 1999).

\section{Creation of mean sum scores}

Since the factor scores generated by a factor analysis are specific to their dataset of origin and are not readily generalizable to other datasets, mean scale scores for the resulting factors were calculated in the final model. This was conducted by dividing the number of items endorsed in the factor by the total number of items in the factor for each subject, resulting in a score between 0 and 1 for each factor. The total number of items endorsed by each individual (total sum score), which corresponds to a one-factor model, was also calculated. These scores were used in the heritability analyses and in correlation analyses with demographic and other clinical characteristics.

\section{Heritability analyses}

Heritability estimates and the corresponding significance levels were calculated for each factor sum score (corresponding to a five-factor model), the total sum score (corresponding to a one-factor model), and the YBOCS severity score. The Sequential Oligogenic Linkage Analysis Routine (SOLAR) statistical package, version 4.0.7 (Almasy and Blangero 1998) was used, employing a variance component approach using information from all available family members across generations without assuming an inheritance model. The resultant heritability statistic $\left(h^{2} r\right)$ is based on a maximum-likelihood-based variance decomposition approach providing an estimate and a confidence interval that are based on the formula: $h^{2}=\mathrm{VG} / \mathrm{VP}$, (where VG is the additive genetic variance and VP is the total phenotypic variance). The proportion of variability in a quantitative trait due to additive genetic and environmental effects is thus estimated. The null hypothesis of no heritability $\left(h^{2} r=0\right)$ is tested by using likelihood ratio tests to compare a "reduced" model (which assumes that none of the observed variation is explained by genes) to a "full" model (which assumes that some fraction of the phenotypic variation is explained by genetic factors). In addition, the degree of shared variance between two quantitative traits due to environmental factors (RhoE) and genetic factors (RhoG) is assessed (Almasy and Blangero 1998). The genetic correlation between two quantitative traits, which is the component of the overall correlation that is due to pleiotropy (i.e., the effect of a gene or set of genes on both traits simultaneously), is obtained from the kinship information contained in the pedigrees. In contrast, the environmental correlation between two quantitative traits is obtained from the estimate of the individual-specific error (Greenwood et al. 2007).

Factors that were deemed likely to affect heritability estimates of the factor sum scores, such as age at interview, gender and YBOCS total severity score were included as covariates in all analyses. To calculate heritabilities for each factor sum score independently of other factor sum scores, the other factors were included as covariates in the analyses of the individual factors. Since neither factor scale scores nor the total sum score were normally distributed, these variables were transformed using inverse normal transformations prior to calculating heritabilities. Pair-wise genetic and environmental correlations (RhoG and RhoE) with corresponding standard errors and significance values were calculated between the symptom factors and YBOCS severity score, and among the symptom factors to explore their etiological relationships. Since standard errors were not computable for factor 4 (superstitions factor containing miscellaneous items), bivariate analyses were not conducted between this factor and the other variables.

Age of onset, gender, familiality and age at assessment were modeled in multiple regression analyses with mean factor scale scores as the dependent variable.

\section{Results}

Demographic and clinical data are summarized in Table 2. The total sample consisted of 1224 subjects, $50.5 \%$ $(n=618)$ of whom were female. Mean ages $( \pm \mathrm{SD})$ were $33.8 \pm 12.6$ years at assessment and $16.0 \pm 9.2$ years at symptom onset $( \pm \mathrm{SD})$. The mean total YBOCS severity score $( \pm \mathrm{SD})$ was $22.6 \pm 8.6$. Data on family history were available for 431 patients, of whom 157 (36.4\%) reported a positive family history for OC symptoms.

The US samples included more males than the Dutch or South-African samples $(p<0.001)$, had a lower age of onset of OC symptoms $(p<0.001)$, and higher YBOCS total $(p<0.001)$, obsession $(p<0.001)$ and compulsion $(p<0.001)$ subscale scores and less often had a positive family history for OC symptoms $(p<0.001)$. Endorsement rates of individual items also differed between sites, being higher in US versus Dutch/South African subjects for all except 9 items, mostly encompassing miscellaneous items. 
Table 2 Subject demographics and clinical characteristics by recruitment site

\begin{tabular}{lclllllcc}
\hline & $N$ & $\begin{array}{l}\text { Sex } \\
\text { (females) } \\
(\%)\end{array}$ & $\begin{array}{l}\text { Age at } \\
\text { assessment } \\
\text { (years) }\end{array}$ & $\begin{array}{l}\text { Age of OC } \\
\text { symptom } \\
\text { onset (years) }\end{array}$ & $\begin{array}{l}\text { YBOCS } \\
\text { severity } \\
\text { score }\end{array}$ & $\begin{array}{l}\text { YBOCS } \\
\text { obsession } \\
\text { score }\end{array}$ & $\begin{array}{l}\text { YBOCS } \\
\text { compulsion } \\
\text { score }\end{array}$ & $\begin{array}{l}\text { Positive } \\
\text { family } \\
\text { history }\end{array}$ \\
\hline Boston & 329 & $(41.5 \%)$ & $32.4 \pm 11.3$ & $15.4 \pm 8.2$ & $27.9 \pm 6.3$ & $14.2 \pm 3.5$ & $13.7 \pm 3.7$ & $29.1 \%$ \\
San Franc. & 124 & $(46.8 \%)$ & $31.9 \pm 13.8$ & $8.8 \pm 4.3$ & $27.1 \pm 7.3$ & $13.7 \pm 3.8$ & $13.4 \pm 4$ & NA \\
Groningen & 149 & $(46.8 \%)$ & $38.7 \pm 11.9$ & $19.0 \pm 10.6$ & $17.4 \pm 7.9$ & $8.2 \pm 4.4$ & $9.1 \pm 4.7$ & NA \\
S.Africa & 393 & $(49.6 \%)$ & $32.2 \pm 13.7$ & $16.7 \pm 9.9$ & $19.0 \pm 8.2$ & NA & NA & NA \\
Amsterdam & 229 & $(56.3 \%)$ & $36.0 \pm 10.9$ & $16.7 \pm 8.3$ & $23.3 \pm 7.9$ & $11.4 \pm 4.2$ & $11.9 \pm 4.7$ & $48.2 \%$ \\
Total cohort & 1224 & $(50.5 \%)$ & $33.8 \pm 12.6$ & $16.0 \pm 9.2$ & $22.6 \pm 8.6$ & $12.1 \pm 4.5$ & $12.2 \pm 4.6$ & NA \\
\hline
\end{tabular}

NA not available

Item-level factor analyses

In the initial exploratory factor analysis, there were 11 eigenvalues $\geq 1$, accounting for $73.3 \%$ of the total variance, and 5 eigenvalues $\geq 2$ accounting for $59 \%$ of the total variance. The first eigenvalue (17.45) accounted for $32 \%$ of the variance; the second (5.2) accounted for $10 \%$ of the additional variance. Examination of the scree plot and eigenvalues from the initial exploratory factor analysis suggested that the most likely best-fit models contained between 4 and 6 factors. Confirmatory factor analyses were conducted for $1,4,5$, and 6 factors since the scree plot dropped abruptly after the first factor. Of the 63 items included in the exploratory analyses, 10 were omitted from the confirmatory factor analyses due to cross-loading (i.e., loading of $>0.3$ on three or more factors), not loading $\geq 0.4$ on any factor, or due to instability across models. These items included: "nonsense sounds", "bothered by certain sounds", "need to tell, ask or confess", "need to touch or rub", "rituals involving blinking or staring", "trichotillomania", "other self-damaging behavior", "excessive concern with illness/disease", "excessive concern with bodily part or appearance", and "checking tied to somatic obsessions". This resulted in the final inclusion of 53 items in the confirmatory factor analyses.

Fit indices for the 1, 4, 5 and 6 factor models are summarized in Table 3. A five factor model demonstrated the best fit, explaining $59 \%$ of the variance. The five factors obtained included: (1) taboo (sexual, aggressive and religious symptoms), (2) contamination/cleaning (contamination obsessions and cleaning compulsions), (3) doubts (obsessions related to fears of having caused harm to self or others, and checking compulsions related to these fears), (4) rituals/superstition (superstitious obsessions and compulsions such as lucky numbers or colors, rituals such as ritualized eating behaviors, and mental rituals) and (5) hoarding/symmetry (hoarding obsessions and compulsions, symmetry, ordering and arranging compulsions, and symptoms related to fear of losing things or making an
Table 3 Confirmatory factor analyses fit indices for the 1, 4, 5 and 6 factor solutions

\begin{tabular}{|c|c|c|c|c|}
\hline $\begin{array}{l}\text { Number of factors in } \\
\text { model }\end{array}$ & 1 & 4 & 5 & 6 \\
\hline CFI & 0.384 & 0.724 & 0.746 & 0.742 \\
\hline TLI & 0.768 & 0.902 & 0.911 & 0.910 \\
\hline RMSEA & 0.114 & 0.074 & 0.071 & 0.071 \\
\hline WRMR & 3.424 & 2.312 & 2.203 & 0.2000 \\
\hline$\chi^{2}(\mathrm{df})$ & 1168.21 & $180.546(4)$ & 8.959 (4) & - \\
\hline$p$-value & $<0.0001$ & $<0.0001$ & 0.0624 & - \\
\hline
\end{tabular}

CFI comparative fit index, TLI Tucker-Lewis index, RMSEA root mean square error of approximation, WRMR weighted root mean square residual

error). Cronbach's alpha coefficients ranged between 0.73 and 0.87 , indicating good internal consistency of the factors, and scale intercorrelations ranged between 0.36 and 0.64 (all statistically significant at $p<0.0001$ ). Item loadings for the five factor model are displayed in Table 4 .

\section{Categorical factor analysis}

Categorical factor analysis using 13 of the 15 predefined symptom categories, and excluding the miscellaneous categories, yielded 4 factors explaining $65.5 \%$ of the variance (data not shown): Factor 1: symmetry obsessions, ordering and arranging, counting and repeating compulsions; Factor 2: aggressive, sexual and religious obsessions and checking compulsions; Factor 3: contamination obsessions and cleaning compulsions; and Factor 4: hoarding obsession and compulsions.

\section{Heritability analyses (Tables 5 and 6)}

All item-derived symptom factors were heritable when other symptom factors were controlled for, with heritability estimates ranging between 0.24 for the contamination/cleaning factor and 0.44 for the doubts factor. The total sum score 
Table 4 Factor loadings, eigenvalues and variance explained for the best fit, five factor model

\begin{tabular}{|c|c|c|c|c|c|}
\hline & $\begin{array}{l}\text { Factor } 1 \\
\text { Taboo }\end{array}$ & $\begin{array}{l}\text { Factor } 2 \\
\text { Contamination/ } \\
\text { cleaning }\end{array}$ & $\begin{array}{l}\text { Factor } 3 \\
\text { Doubts }\end{array}$ & $\begin{array}{l}\text { Factor } 4 \\
\text { Rituals/ } \\
\text { superstition }\end{array}$ & $\begin{array}{l}\text { Factor } 5 \\
\text { Hoarding, } \\
\text { symmetry }\end{array}$ \\
\hline Forbidden/perverse thoughts, images, impulses & $\mathbf{0 . 8 8}$ & 0.10 & 0.02 & 0.10 & 0.00 \\
\hline Content involves children on incest & 0.84 & 0.15 & 0.03 & 0.04 & -0.09 \\
\hline Sexual behavior towards others & 0.82 & 0.14 & 0.07 & 0.22 & 0.12 \\
\hline Obsessions involving homosexuality & 0.81 & 0.17 & 0.00 & 0.21 & -0.10 \\
\hline Violent or horrific images & 0.70 & 0.09 & 0.17 & 0.17 & 0.11 \\
\hline Fear will act on unwanted impulses & 0.70 & 0.00 & 0.38 & 0.05 & 0.14 \\
\hline Fear of blurting obscenities/insults & 0.66 & 0.08 & 0.31 & 0.00 & 0.21 \\
\hline Fear will steal things & 0.62 & 0.27 & 0.27 & 0.09 & 0.38 \\
\hline Fear of doing something embarrassing & 0.60 & 0.12 & 0.25 & 0.08 & 0.38 \\
\hline Fear might harm self & 0.58 & 0.09 & 0.20 & 0.26 & 0.10 \\
\hline Concern with sacrilege/blasphemy & 0.56 & 0.20 & 0.17 & 0.26 & 0.01 \\
\hline Intrusive (nonviolent) images & 0.52 & 0.14 & 0.01 & 0.41 & 0.12 \\
\hline Concern with right/wrong, morality & 0.48 & 0.14 & 0.30 & 0.28 & 0.10 \\
\hline Concern with dirt or germs & 0.10 & 0.92 & 0.13 & 0.03 & 0.06 \\
\hline Excessive/ritualized hand washing & -0.04 & 0.88 & 0.15 & 0.16 & 0.01 \\
\hline Other measures to prevent/remove contaminants & 0.12 & 0.81 & 0.10 & 0.19 & 0.03 \\
\hline Concerns with bodily secretions & 0.27 & 0.78 & 0.16 & 0.08 & 0.01 \\
\hline Cleaning household items/objects & -0.04 & 0.74 & 0.06 & 0.15 & 0.26 \\
\hline Excessive showering, grooming & -0.03 & 0.73 & 0.02 & 0.25 & 0.24 \\
\hline Excessive concern with animals & 0.23 & 0.73 & 0.10 & 0.10 & 0.17 \\
\hline Bothered by sticky substances & 0.13 & 0.72 & 0.02 & 0.19 & 0.19 \\
\hline Concern with household cleaners & 0.20 & 0.70 & 0.21 & 0.14 & 0.17 \\
\hline Concern with environmental contaminants & 0.26 & 0.66 & 0.24 & 0.12 & 0.00 \\
\hline Concerned will get ill because of contaminant & 0.26 & 0.62 & 0.33 & 0.12 & -0.02 \\
\hline Concern about contaminants & 0.02 & 0.57 & -0.20 & -0.07 & 0.17 \\
\hline Checking that did not harm others & 0.32 & 0.10 & 0.81 & 0.12 & -0.02 \\
\hline Fear will be responsible for something terrible happening & 0.19 & 0.10 & 0.76 & 0.15 & 0.08 \\
\hline Fear might harm others & 0.37 & 0.20 & 0.73 & 0.05 & 0.09 \\
\hline Checking that nothing terrible did/will happen & 0.25 & 0.13 & 0.72 & 0.27 & 0.06 \\
\hline Checking locks, stoves, appliances & -0.19 & 0.09 & 0.63 & 0.08 & 0.30 \\
\hline Checking that did not make mistake & 0.06 & 0.16 & 0.60 & 0.15 & 0.44 \\
\hline Fear might harm others because not careful enough & 0.59 & -0.02 & 0.59 & 0.00 & 0.03 \\
\hline Checking did not harm self & 0.37 & 0.27 & $\mathbf{0 . 5 3}$ & 0.25 & 0.15 \\
\hline Concerned will make others ill & 0.29 & 0.49 & 0.51 & 0.10 & -0.06 \\
\hline Superstitious behaviors & 0.20 & 0.20 & 0.14 & 0.76 & 0.08 \\
\hline Lucky/unlucky numbers & 0.18 & 0.11 & 0.07 & 0.73 & 0.16 \\
\hline Superstitious fears & 0.21 & 0.17 & 0.17 & 0.73 & -0.02 \\
\hline Need to repeat routine activities & 0.00 & 0.05 & 0.11 & 0.69 & 0.28 \\
\hline Colors with special significance & 0.19 & 0.23 & 0.11 & 0.60 & 0.11 \\
\hline Counting compulsions & 0.05 & 0.08 & 0.11 & 0.52 & 0.42 \\
\hline Ritualized eating behaviors & 0.21 & 0.23 & -0.02 & 0.48 & 0.33 \\
\hline Mental rituals & 0.34 & 0.05 & 0.13 & 0.45 & 0.20 \\
\hline Measures (not checking) to prevent harm or terrible consequences & 0.32 & 0.13 & 0.39 & $\mathbf{0 . 4 3}$ & -0.04 \\
\hline Ordering/arranging compulsions & 0.00 & 0.18 & -0.03 & 0.27 & 0.71 \\
\hline Hoarding obsesions & 0.25 & 0.17 & 0.04 & 0.12 & 0.63 \\
\hline Symmetry obsessions & -0.03 & 0.18 & -0.07 & 0.22 & 0.62 \\
\hline Hoarding compulsions & 0.20 & 0.14 & 0.06 & 0.16 & 0.62 \\
\hline
\end{tabular}


Table 4 continued

\begin{tabular}{|c|c|c|c|c|c|}
\hline & $\begin{array}{l}\text { Factor } 1 \\
\text { Taboo }\end{array}$ & $\begin{array}{l}\text { Factor } 2 \\
\text { Contamination/ } \\
\text { cleaning }\end{array}$ & $\begin{array}{l}\text { Factor } 3 \\
\text { Doubts }\end{array}$ & $\begin{array}{l}\text { Factor } 4 \\
\text { Rituals/ } \\
\text { superstition }\end{array}$ & $\begin{array}{l}\text { Factor } 5 \\
\text { Hoarding/ } \\
\text { symmetry }\end{array}$ \\
\hline Excessive listmaking & -0.09 & -0.06 & 0.11 & -0.12 & 0.59 \\
\hline Fear of losing things & 0.18 & 0.12 & 0.37 & 0.17 & 0.58 \\
\hline Re-reading, re-writing & 0.08 & 0.13 & 0.19 & 0.45 & 0.49 \\
\hline Need to know, remember & 0.34 & 0.10 & 0.15 & 0.30 & 0.46 \\
\hline Fear of not saying the right thing & 0.27 & 0.18 & 0.26 & 0.23 & 0.42 \\
\hline Cronbach's alpha & 0.85 & 0.87 & 0.81 & 0.74 & 0.73 \\
\hline Eigenvalue & 17.5 & 5.2 & 3.9 & 2.9 & 2.1 \\
\hline Variance explained (\%) & 0.32 & 0.10 & 0.07 & 0.05 & 0.04 \\
\hline Cumulative variance explained (\%) & 0.32 & 0.42 & 0.49 & 0.55 & 0.58 \\
\hline
\end{tabular}

Numbers depicted in bold indicate items with factor loadings $>0.4$ which were included in the corresponding factor in the calculation of the mean score per items for this factor

Table 5 Heritabilities for the factors of the YBOCS-CL

\begin{tabular}{llll}
\hline & $H^{2} r$ & SE & $p$-Value \\
\hline Phenotype: item-level derived factors & & & \\
Factor 1 (Taboo) factor scale score & 0.26 & 0.12 & 0.006 \\
Factor 2 (Contamination/cleaning) factor scale score & 0.24 & 0.13 & 0.03 \\
Factor 3 (Doubts) factor scale score & 0.44 & 0.12 & 0.00002 \\
Factor 4 (Rituals/superstition) factor scale score & 0.34 & 0.16 & 0.009 \\
Factor 5 (hoarding/symmetry) factor scale score & 0.35 & 0.12 & 0.001 \\
YBOCS total sum score (one-factor model) & 0.39 & 0.15 & 0.004 \\
YBOCS total severity score & 0.52 & 0.13 & 0.00005 \\
Phenotype: category-derived factors & & & \\
Factor 1 (Symmetry/counting) & 0.00 & $\mathrm{NA}$ & $\mathrm{n} . \mathrm{s}$. \\
Factor 2 (Aggressive/sexual/religious) & 0.58 & 0.17 & 0.00006 \\
Factor 3 (Contamination/cleaning) & 0.32 & 0.14 & 0.006 \\
Factor 4 (Hoarding) & 0.23 & 0.15 & 0.04 \\
\hline
\end{tabular}

(corresponding to a one factor model) and the YBOCS total severity score were also heritable, with heritability estimates of 0.39 and 0.52 , respectively. Bivariate genetic analyses revealed shared environmental influences with YBOCS severity for all symptom factors, with estimates (RhoEs) ranging between 0.36 and 0.63 . The hoarding/symmetry factor and the contamination/cleaning factor also shared genetic influences with YBOCS severity, with estimated (RhoGs) of $0.78(p=0.0005)$ and $0.48 \quad(p=0.04)$, respectively. The total sum score (one-factor model) showed shared genetic (RhoG 0.72, $p=0.002$ ) and environmental (RhoE 0.57, $p=0.001$ ) influences with YBOCS severity as well. Further, shared environmental influences were found between nearly all factors, with RhoE's between 0.28 (between taboo and contamination) and 0.66 (between doubts and hoarding-symmetry). Shared genetic influences were identified between 'taboo' and 'doubts $(\mathrm{RhoG}=0.80)$ and between 'contamination/cleaning' and 'hoarding/symmetry'; RhoG =0.77 (Table 6).
Of the categorical four factors, all factors except the symmetry factor were heritable, with heritabilities ranging between 0.23 and 0.58 (Table 5). Bivariate genetic analyses revealed no shared genetic influences, but shared environmental influences were identified between 'obsessions and checking' and all other factors (RhoE's between 0.23 and 0.58 ; data not shown).

Regression analyses between factor scores and clinical characteristics

For all factors, increased scores were associated with earlier age of onset (Table 7; $\beta$ 's between -0.24 and -0.12). Scores of the taboo factor were significantly higher in males than in females, and the taboo and symmetry/ hoarding factors were negatively associated with age at assessment ( $\beta$ 's of -0.21 and -0.12 ). No relationships were found between family history of OCD and factors. 
Table 6 Bivariate genetic analyses $(n=258)$

\begin{tabular}{|c|c|c|c|c|c|c|}
\hline & RhoG & SE & $p$-Value & RhoE & SE & $p$-Value \\
\hline \multicolumn{7}{|l|}{ Phenotype: item-derived factors/YBOCS severity } \\
\hline Factor 1 (Taboo) factor scale score & 0.41 & 0.24 & n.s. & 0.36 & 0.15 & 0.03 \\
\hline Factor 2 (Contamination/cleaning) factor scale score & 0.48 & 0.19 & 0.04 & 0.41 & 0.14 & 0.01 \\
\hline Factor 3 (Doubts) factor scale score & 0.39 & 0.19 & n.s. & 0.44 & 0.14 & 0.009 \\
\hline Factor 4 (Superstitions) factor scale score & 0.15 & 0.41 & n.s. & 0.63 & 0.11 & $3.4 \times \mathrm{e}^{-6}$ \\
\hline Factor 5 (hoarding/symmetry) factor scale score & 0.78 & 0.10 & 0.0005 & 0.43 & 0.13 & 0.02 \\
\hline YBOCS total sum score (one factor-model) & 0.72 & 0.13 & 0.002 & 0.57 & 0.12 & 0.001 \\
\hline \multicolumn{7}{|l|}{ Phenotype: item-derived factors } \\
\hline Factor 1 (taboo)/Factor 2 (contamination) & 0.26 & 0.34 & n.s. & 0.28 & 0.14 & 0.05 \\
\hline Factor 1 (taboo)/Factor 3 (doubts) & 0.80 & 0.22 & 0.01 & 0.24 & 0.15 & n.s. \\
\hline Factor 1 (taboo)/Factor 5 (hoarding/symmetry) & 0.39 & 0.32 & n.s. & 0.52 & 0.11 & 0.003 \\
\hline Factor 2 (taboo)/Factor 3 (doubts) & 0.50 & 0.22 & n.s. & 0.41 & 0.13 & 0.02 \\
\hline Factor 2 (taboo)/Factor 5 (hoarding/symmetry) & 0.77 & 0.17 & 0.02 & 0.38 & 0.13 & 0.05 \\
\hline Factor 3 (doubts)/Factor 5 (hoarding/symmetry) & 0.48 & 0.24 & n.s. & 0.66 & 0.10 & 0.001 \\
\hline
\end{tabular}

$R h o G$ shared genetic variance, $R h o E$ shared environmental variance, $S E$ standard error, $n s$ not significant $(p>0.05)$

Table 7 Multiple regression analyses of factor scores using gender, age at assessment, and age of onset of OC symptoms as predictors

\begin{tabular}{|c|c|c|c|c|}
\hline Multiple regression model $(n=1024)$ & $R^{2}$ & $\begin{array}{l}\text { Gender } \\
(p \text {-value })\end{array}$ & $\begin{array}{l}\text { Age at assessment } \\
(p \text {-value) }\end{array}$ & $\begin{array}{l}\text { Age of } \\
\text { onset ( } p \text {-value) }\end{array}$ \\
\hline Factor 1 (Taboo) factor scale score & 0.066 & 0.001 & 0.003 & $<0.001$ \\
\hline Factor 2 (Contamination/cleaning) factor scale score & 0.023 & n.s. & n.s. & $<0.001$ \\
\hline Factor 3 (Doubts) factor scale score & 0.016 & n.s. & n.s. & $<0.001$ \\
\hline Factor 4 (Superstitions) factor scale score & 0.058 & n.s. & n.s. & $<0.001$ \\
\hline Factor 5 (Hoarding/symmetry) factor scale score & 0.039 & n.s. & 0.003 & $<0.001$ \\
\hline YBOCS total symptom score (one factor model) & 0.053 & 0.038 & n.s. & $<0.001$ \\
\hline
\end{tabular}

\section{Discussion}

This is the largest item-level factor-analytic and heritability study conducted to date for OC symptoms. The sample size of 1224 affected subjects provides analytic power previously unavailable for OCD symptom dimension research. Results support the assertion that both OCD and its symptom dimensions are heritable and, thus, are of value for use in future genetics research. They also raise the possibility that the genes and gene networks underlying common susceptibility to OCD differ from those underlying distinct symptom dimensions. Consistent with previous smaller item-level factor-analytic studies, five symptom factors have been identified, i.e.: (1) taboo (religious, sexual, and aggressive obsessions) symptoms, (2) contamination and cleaning symptoms, (3) doubts (fears of harming self or others, doubting and checking symptoms), (4) superstitions and rituals, and (5) hoarding and symmetry symptoms (including perfectionism). This symptom dimension model reveals substantial overlap with the factor structures identified in previous item-level analyses,
(Denys et al. 2004; Feinstein et al. 2003; Girishchandra and Khanna 2001; Hantouche and Lancrenon 1996; Pinto et al. 2008; Stein et al. 2007, 2008; Wu et al. 2007), with two key differences. First, somatic items did not load consistently on any of the factors, and second, the rituals/superstition factor is new, containing predominantly miscellaneous items excluded from most previous studies.

The first distinction between this and other item-level factor analyses that somatic items on the YBOCS-CL did not load consistently on any factors, is consistent with a recent study by Cullen et al. (2007). In the present sample, better fit and more stable solutions were obtained when somatic items were omitted from analyses. This finding suggests that some somatic items, although often clinically co-occurring with OCD, do not represent core OC symptoms and may contribute to observed phenotypic and genotypic OCD heterogeneity. Instead, the somatic items may be related to hypochondriasis, a frequently comorbid illness with OCD (Bienvenu et al. 2000). Recent phenomenological and neuroimaging studies have shown a clear distinction between hypochondriasis and OCD, despite 
some shared phenotypic and brain function characteristics (Greeven et al. 2006; van den Heuvel et al. 2005).

The second notable distinction between this and previous item-level factor analyses is the emergence of a rituals/ superstition factor. This is mainly comprised of items from the miscellaneous YBOCS-CL sections, which were excluded from past studies. However, it is unclear whether this new factor reflects either a subdomain of the OCD phenotype or a co-occurring symptom dimension that is more distally etiologically related to OCD. Although heritability was demonstrated for this dimension, and may potentially be of use for clinical outcome research, one might consider omitting this factor from future studies. Indeed, the inability to perform reliable bivariate genetic analyses using this factor, coupled with the difficulty of interpreting its symptom constituents illustrates a weakness of the YBOCS-CL, i.e. that over the years items have been added to the scale without investigating whether the items are in fact OCD-related, carrying the risk of introducing phenotypic bias.

This study provides evidence that OCD diagnosis may be dissected into non-mutually exclusive, consistent and homogeneous symptom dimensions, given the stability of symptoms within factors across models, the high internal consistency of the factors, and the high heritability estimates of the factors. Of note, the category-based factor analysis conducted on this sample yielded similar results to those previously reported in other samples (rather than being similar to the item-level analysis on this sample). Direct comparison of the item-level and category-based FAs in this study showed similarities only for the factors contamination/washing, and for the taboo factor of the item-level analysis and the obsession factor of the category-based FA.

Previous heritability studies that used category-based analyses predominantly used sib-sib correlations and yielded mixed results, especially with respect to heritability estimates of the symmetry/ordering factor (Chacon et al. 2007; Cullen et al. 2007; Hasler et al. 2007). This study, in which the symmetry factor obtained using the categorybased approach was not heritable, corroborates these inconsistent findings. Interestingly, consistent with the first categorical factor analyses in OCD (Baer 1994), the itemlevel approach resulted in hoarding/symmetry behaviors constituting a heritable factor in this study. Moreover, this factor showed the highest genetic correlation with a latent or underlying OC susceptibility (as measured by YBOCS severity). This may be an artifact of the available family data, which contained a substantial number of hoarding families, or it may alternatively reflect a genuine relationship between these constructs. This finding, along with the other heritability results, requires replication in an independent sample. Further, the contamination/wash factor showed a significant genetic correlation with underlying OC susceptibility. Interestingly, the contamination and hoarding/symmetry factor showed significant genetic correlations as well, as did the taboo and doubts factor. This latter correlation corroborates previous work in college students and clinical samples strongly suggesting a heritable obsessionality factor strongly related to OCD (Mathews et al. 2008).

Notably, although not providing the best statistical fit for the data, a one-factor model also emerged as a possible solution according to the eigen structure, as evidenced by the scree plot. The heritability analyses suggested that a one-factor solution was at least as heritable as the majority of the individual factors, and that although it shared genetic influences with YBOCS total severity, there were also independent genetic influences for this construct. Thus, although we did not directly test this, the results suggest that, in addition to individual genetic influences determining specific symptom expression, there may be a heritable underlying susceptibility to OC symptoms in general. These findings are in line with (1) a recent populationbased twin study of OC symptom dimensions; (2) a family study of OC symptoms in extended families, both of which found evidence of one heritable underlying latent susceptibility to OC symptoms along with specific genetic contributions to OC symptom dimensions (van Grootheest et al. 2008; Mathews et al. 2008); and (3) with a parallel study on the same data set as used in this study, using latent class analyses, which showed that a three class solution provided the best fit, the classes only differing on level of symptom endorsement. These converging data suggest that OCD as a single entity is a valid model to attain to (De Lucchi et al. in review).

The negative associations between factor scores and age of onset are in concordance with previous research reporting a higher number of obsessions and compulsions and higher symptom severity in subjects with early onset compared to subjects with late onset OCD (Millet et al. 2004). Higher mean scores on the "taboo" factor (aggressive and sexual obsessions) in men than in women is consistent with other reports as well (Torresan et al. 2009). This predominance of aggressive and sexual obsessions among men with OCD holds across cultures (Jaisoorya et al. 2009). Finally, overrepresentation of the "rituals and superstition" factor in men in this study has also been reported previously (Jaisoorya et al. 2009), adding to reported gender differences with respect to phenotypic expression of OCD.

The main methodological strengths of this study include: (1) the large sample size; (2) the use of improved statistical methodology over some previous studies; (3) heritability analyses in large multigenerational families with multiple OCD-affected individuals, thus improving 
the precision of heritability estimates, and (4) generalizability of findings.

The heterogeneity of the sample and the potentially differential application and interpretation of the YBOCS$\mathrm{SC}$ individual items across sites are the principal limitations of this study. No inter-rater reliability data were available across sites on the YBOCS-SC and therefore, substantial variability due to measurement error cannot be ruled out. Moreover, some sites measured current endorsement whereas others measured lifetime endorsement. Paradoxically, the sample heterogeneity may also be viewed as a principal strength. Although such heterogeneity may theoretically contribute to the instability of resulting models, the ultimate best-fit model was remarkably stable and most likely a result of the large sample size. The sample heterogeneity also increases generalizability of the findings to other OCD samples. Although the individual items within YBOCS-CL categories are not operationally defined, and their psychometric properties seem to be weaker than some other measures used in OCD research contexts, the YBOCS is arguably the most extensively used clinical assessment of obsessive-compulsive symptoms worldwide, and is easily completed both by OCD-affected individuals and clinicians. Use of this instrument in these analyses adds to the interpretability and accessibility of the results by clinicians using the YBOCS in their practice, and facilitates replication efforts on additional samples. An additional perceived study limitation may be the number of families available for the heritability analyses, which was relatively small compared to appropriately powered twin studies. However, the number and pedigree structures of the families included here have sufficient a priori power to detect heritability estimates of $30 \%$ or higher, according to Schork and Schork (1993). An advantage of this approach over a twin-family approach is that relatively small numbers of families are required, increasing the feasibility for a replication in subsequent studies.

In summary, in the face of an emerging need to refine the OCD phenotype for genetic, clinical and translational studies, these results provide evidence for ongoing utility of both the OCD DSM phenotype as a whole and of specific OC symptom dimension subgroups. An item-level derived five factor model accounts for a similar proportion of explained symptom variance as category-derived models. Moreover, supporting recently emergent twin and family study findings, heritability calculations suggest the presence of both common and distinct biologic underpinnings of OCD and its symptom dimensions. They bolster the current hypothesis that OCD is genetically complex, with multiple genetic and environmental factors contributing to its development.
Acknowledgments This work was supported in part by the Obsessive-Compulsive Foundation (Boston, USA), the Tourette Syndrome Association (Bayside, New York), the Anxiety Disorders Association of America (Boston, USA), the American Academy of Child and Adolescent Psychiatry (USA) and NARSAD (New York, USA).

Open Access This article is distributed under the terms of the Creative Commons Attribution Noncommercial License which permits any noncommercial use, distribution, and reproduction in any medium, provided the original author(s) and source are credited.

\section{References}

Almasy L, Blangero J (1998) Multipoint quantitative-trait linkage analysis in general pedigrees. Am J Hum Genet 62:1198-1211

Alsobrook IJ, Leckman JF, Goodman WK et al (1999) Segregation analysis of obsessive-compulsive disorder using symptom-based factor scores. Am J Med Genet 88:669-675

American Psychiatric Association (1994) Diagnostic and statistical manual of mental disorders, 4th edition edn. American Psychiatric Association, Washington, DC

Baer L (1994) Factor analysis of symptom subtypes of obsessive compulsive disorder and their relation to personality and tic disorders. J Clin Psychiatry 55:18-23

Bienvenu OJ, Samuels JF, Riddle MA et al (2000) The relationship of obsessive-compulsive disorder to possible spectrum disorders: results from a family study. Biol Psychiatry 48:287-293

Bloch MH, Landeros-Weisenberger A, Rosario MC et al (2008) Meta-analysis of the symptom structure of obsessive-compulsive disorder. Am J Psychiatry 165:1532-1542

Browne MW, Cudek R (1993) Alternative ways of assessing model fit. In: Long JS (ed) Testing structural equation models. Sage, Newbury Park, CA, pp 136-162

Cavallini MC, Di Bella D, Siliprandi F et al (2002) Exploratory factor analysis of obsessive-compulsive patients and association with 5-HTTLPR polymorphism. Am J Med Genet 114:347-353

Chacon P, Rosario-Campos MC, Pauls DL et al (2007) Obsessivecompulsive symptoms in sibling pairs concordant for obsessivecompulsive disorder. Am J Med Genet B Neuropsychiatr Genet 144B:551-555

Chavira DA, Garrido H, Bagnarello M et al (2008) A comparative study of obsessive-compulsive disorder in Costa Rica and the United States. Depress Anxiety 25:609-619

Cullen B, Brown CH, Riddle MA et al (2007) Factor analysis of the Yale-Brown obsessive compulsive scale in a family study of obsessive-compulsive disorder. Depress Anxiety 24:130-138

Delorme R, Bille A, Betancur C et al (2006) Exploratory analysis of obsessive compulsive symptom dimensions in children and adolescents: a prospective follow-up study. BMC Psychiatry 6:1

Denys D, de Geus F, van Megen HJ et al (2004) Use of factor analysis to detect potential phenotypes in obsessive-compulsive disorder. Psychiatry Res 128:273-280

Feinstein SB, Fallon BA, Petkova E et al (2003) Item-by-item factor analysis of the Yale-Brown obsessive compulsive scale symptom checklist. J Neuropsychiatry Clin Neurosci 15:187-193

First MB, Spitzer RL, Gobbon M et al (1998) Structured clinical interview for DSM-IV Axis 1 disorders - Patient Edition (SCIDI/P, Version 2.0, 8/98 revision). New York State Psychiatric Institute, Biometrics department, New York

Fontenelle LF, Hasler G (2008) The analytical epidemiology of obsessive-compulsive disorder: risk factors and correlates. Prog Neuropsychopharmacol Biol Psychiatry 32:1-15 
Girishchandra BG, Khanna S (2001) Phenomenology of obsessive compulsive disorder: a facor analytic approach. Indian $\mathrm{J}$ Psychiatry 43:306-316

Goodman WK, Price LH, Rasmussen SA et al (1989a) The YaleBrown obsessive compulsive scale. II. Validity. Arch Gen Psychiatry 46:1012-1016

Goodman WK, Price LH, Rasmussen SA et al (1989b) The YaleBrown obsessive compulsive scale. I. Development, use, and reliability. Arch Gen Psychiatry 46:1006-1011

Greenwood TA, Braff DL, Light GA et al (2007) Initial heritability analyses of endophenotypic measures for schizophrenia: the consortium on the genetics of schizophrenia. Arch Gen Psychiatry $64: 1242-1250$

Greeven A, van Balkom AJ, van Rood YR et al (2006) The boundary between hypochondriasis and obsessive-compulsive disorder: a cross-sectional study from the Netherlands. J Clin Psychiatry 67:1682-1689

Hantouche EG, Lancrenon S (1996) Modern typology of symptoms and obsessive-compulsive syndromes: results of a large French study of 615 patients. Encephale 22(1):9-21

Hasler G, LaSalle-Ricci VH, Ronquillo JG et al (2005) Obsessivecompulsive disorder symptom dimensions show specific relationships to psychiatric comorbidity. Psychiatry Res 135: $121-132$

Hasler G, Pinto A, Greenberg BD et al (2007) Familiality of factor analysis-derived YBOCS dimensions in OCD-affected sibling pairs from the OCD Collaborative Genetics Study. Biol Psychiatry 61:617-625

Hemmings SM, Kinnear CJ, Van der Merwe L et al (2008) Investigating the role of the brain-derived neurotrophic factor (BDNF) val66met variant in obsessive-compulsive disorder (OCD). World J Biol Psychiatry 9:126-134

Hu L, Bentler PM (1999) Cutoff criteria for fit indexes in covariance structure analysis: conventional criteria versus new alternatives. Struc Equ Model 6:1-55

Jaisoorya TS, Reddy YC, Srinath S et al (2009) Sex differences in Indian patients with obsessive-compulsive disorder. Compr Psychiatry 50:70-75

Kim SJ, Lee HS, Kim CH (2005) Obsessive-compulsive disorder, factor-analyzed symptom dimensions and serotonin transporter polymorphism. Neuropsychobiology 52:176-182

Labad J, Menchon JM, Alonso P et al (2008) Gender differences in obsessive-compulsive symptom dimensions. Depres Anxiety $25: 832-838$

Leckman JF, Grice DE, Boardman J et al (1997) Symptoms of obsessive-compulsive disorder. Am J Psychiatry 154:911-917

Mataix-Cols D, Rauch SL, Manzo PA et al (1999) Use of factoranalyzed symptom dimensions to predict outcome with serotonin reuptake inhibitors and placebo in the treatment of obsessivecompulsive disorder. Am J Psychiatry 156:1409-1416

Mataix-Cols D, Rosario-Campos MC, Leckman JF (2005) A multidimensional model of obsessive-compulsive disorder. Am J Psychiatry 162:228-238

Mataix-Cols D, Pertusa A, Leckman JF (2007) Issues for DSM-V: how should obsessive-compulsive and related disorders be classified? Am J Psychiatry 164:1313-1314

Mataix-Cols D, Nakatani E, Micali N et al (2008) Structure of obsessive-compulsive symptoms in pediatric OCD. J Am Acad Child Adolesc Psychiatry 47:773-778

Mathews CA, Nievergelt CM, Azzam A et al (2007) Heritability and clinical features of multigenerational families with obsessivecompulsive disorder and hoarding. Am J Med Genet B Neuropsychiatr Genet 144:174-182
Mathews CA, Greenwood T, Wessel J et al (2008) Evidence for a heritable unidimensional symptom factor underlying obsessionality. Am J Med Genet B Neuropsychiatr Genet 147B:676-685

McKay D, Piacentini J, Greisberg S et al (2006) The structure of childhood obsessions and compulsions: dimensions in an outpatient sample. Behav Res Ther 44:137-146

Millet B, Kochman F, Gallarda T et al (2004) Phenomenological and comorbid features associated in obsessive-compulsive disorder: influence of age of onset. J Affect Disord 79:241-246

Pauls DL (2008) The genetics of obsessive compulsive disorder: a review of the evidence. Am J Med Genet C Semin Med Genet 148C:133-139

Pinto A, Greenberg BD, Grados MA et al (2008) Further development of YBOCS dimensions in the OCD collaborative genetics study: symptoms vs. categories. Psychiatry Res 160:83-93

Samuels JF, Bienvenu OJ, Grados MA et al (2008) Prevalence and correlates of hoarding behavior in a community-based sample. Behav Res Ther 46:836-844

Schafer JL (1999) Multiple imputation: a primer. Stat Methods Med Res 8:3-15

Schork NJ (1993) The design and use of variance component models in the analysis of human quantitative pedigree data. Biom $\mathbf{J}$ 35:387-405

Schork NJ, Schork MA (1993) The relative efficiency and power of small-pedigree studies of the heritability of a quantitative trait. Hum Hered 43:1-11

Sheehan DV, Lecrubier Y, Sheehan KH et al (1998) The miniinternational neuropsychiatric interview (M.I.N.I.): the development and validation of a structured diagnostic psychiatric interview for DSM-IV and ICD-10. J Clin Psychiatry 59(20): 22-33 quiz 34-57

Stein DJ, Andersen EW, Overo KF (2007) Response of symptom dimensions in obsessive-compulsive disorder to treatment with citalopram or placebo. Rev Bras Psiquiatr 29:303-307

Stein DJ, Carey PD, Lochner C et al (2008) Escitalopram in obsessive-compulsive disorder: response of symptom dimensions to pharmacotherapy. CNS Spectr 13:492-498

Stewart SE, Stack DE, Farrell C et al (2005) Effectiveness of intensive residential treatment (IRT) for severe, refractory obsessive-compulsive disorder. J Psychiatr Res 39:603-609

Stewart SE, Rosario MC, Brown TA et al (2007) Principal components analysis of obsessive-compulsive disorder symptoms in children and adolescents. Biol Psychiatry 61:285-291

Stewart SE, Rosario MC, Baer L et al (2008) Four-factor structure of obsessive-compulsive disorder symptoms in children, adolescents, and adults. J Am Acad Child Adolesc Psychiatry 47: 763-772

Torresan RC, Ramos-Cerqueira AT, de Mathis MA et al (2009) Sex differences in the phenotypic expression of obsessive-compulsive disorder: an exploratory study from Brazil. Compr Psychiatry 50:63-69

van den Heuvel OA, Veltman DJ, Groenewegen HJ et al (2005) Disorder-specific neuroanatomical correlates of attentional bias in obsessive-compulsive disorder, panic disorder, and hypochondriasis. Arch Gen Psychiatry 62:922-933

van Grootheest DS, Boomsma DI, Hettema JM et al (2008) Heritability of obsessive-compulsive symptom dimensions. Am J Med Genet B Neuropsychiatr Genet 147B:473-478

Wu KD, Watson D, Clark LA (2007) A self-report version of the Yale-Brown obsessive-compulsive scale symptom checklist: psychometric properties of factor-based scales in three samples. J Anxiety Disord 21:644-661 